\title{
PRAÇAS GREGAS X PRAÇAS DE PRESIDENTE PRUDENTE/SP - BREVE ANÁLISE
}

Thiago Yugo Nagai Matsutane, Gabriel Morais Bianchini, Marcela do Carmo Vieira, Yeda Ruiz Maria Universidade do Oeste Paulista - UNOESTE. Curso de Arquitetura e Urbanismo, Presidente Prudente - SP.

\section{RESUMO}

As praças são locais onde as pessoas se reúnem para fins comerciais, políticos, sociais ou religiosos, ou ainda, onde se desenvolvem atividades de entretenimento. As praças gregas eram surpreendente: o espaço assimétrico, a forma de como trabalham com os volumes, de maneira que eles conseguem trabalhar com a natureza e a paisagem, ou seja, a praça constitui-se de fato como um elemento marcante e de significativa importância no desenho da cidade. As praças, nos dias atuais, passaram a ser valorizados para a vida urbana, com atributos ambientais, estético, e simbólico, em contraste a caótica vida urbana das cidades e a outros espaços característicos da atualidade. Presente artigo tem como objetivo estruturar um paralelo de análise entre as praças gregas antigas com as atuais, em específico a Praça dos Imigrantes, localizada no Jardim das Rosas em Presidente Prudente - São Paulo.

Palavras-chave: Praças atuais. Praças Gregas. Praça dos Imigrantes. Presidente Prudente-SP

\section{GREEK SQUARES X SQUARES OF PRESIDENTE PRUDENTE/SP- BRIEF ANALYSIS}

\section{ABSTRACT}

The squares are places where people gather for commercial, political, social or religious purposes, or, where they develop entertainment activities. Greek squares were surprising: the asymmetrical space, the way they work with the volumes so that they can work with nature and the landscape, ie, the square is made up of fact and as a striking element of significant importance the design of the city. Squares, today, have come to be valued for urban living with environmental, aesthetic, and symbolic attributes, in contrast to chaotic urban life of cities and other spaces characteristic of today. This article aims to design a parallel analysis between the ancient Greek squares with the current, in particular the Immigrant Square, located in the Rose Garden in Presidente Prudente São Paulo.

Keywords: current Squares. Greek squares. Square of Immigrants. Presidente Prudente-SP 


\section{INTRODUÇÃO}

As praças são locais onde as pessoas se reúnem para fins comerciais, políticos, sociais ou religiosos, ou ainda, onde se desenvolvem atividades de entretenimento. (Rigotti, 2005) A praça em si estabelece um ponto de encontro entre as pessoas para a sua relação social, assim como as praças gregas que possuíam essa grande importância, já que eram o local exato das pessoas se encontrarem, um "grande local aberto de reunião" (ROLNIK, 1995).

Nesta vertente as características das praças da Grécia antiga, as quais passou a possuir a infraestrutura urbana, subdividida em duas partes, sendo ela a acrópole e a ágora. $\mathrm{O}$ autor ainda conceitua a acrópole como sendo o primeiro lugar dos templos dos deuses, a parte mais alta da cidade onde ela se inicia e seguindo o crescimento da cidade, nas partes baixas se encontra a ágora, o centro da vida política, o lugar de debates de todo tipo de cidadão, das relações civis, local mais apropriado para o ponto de encontro como cerimônias e assembléias públicas, e com a sua função social e política consegue uma grande importância aos edifícios públicos desta praça, como pórticos ornamentados, fontes e estátuas (COULANGES, 1975).

Enfatiza ainda que a qualidade arquitetônica das praças gregas era surpreendente: o espaço assimétrico, a forma de como trabalham com os volumes, de maneira que eles conseguem trabalhar com a natureza e a paisagem, ou seja, a praça constitui-se de fato como um elemento marcante e de significativa importância no desenho da cidade (DELFANTES, 2000).

O século XXI tem sido um desafio, pois com a vida caótica urbana a pessoa não tem muito tempo para parar, a tecnologia se torna um meio de resolver os problemas, com a internet e suas revoluções é possível solucionar qualquer problema a distância sem precisar se juntar com uma multidão em um único lugar. O que torna mais visível esse ajuntamento de pessoas para a melhoria urbana, política e social seriam as manifestações contra o governo (ROLINK, 1995).

Os espaços livres como as praças, nos dias atuais, passaram a ser valorizados para a vida urbana, com atributos ambientais, estético, e simbólico, em contraste a caótica vida urbana das cidades e a outros espaços característicos da atualidade, como shoppings centers, espaços impessoais opostos aos das praças. Porém, as praças contemporâneas, apesar de deverem propiciar o encontro, o convívio social e o lazer, têm sofrido com o uso seletivo ou desuso, em função de projetos inadequados, apropriações indevidas e perda do significado urbanístico (SUN, 2008).

Nesta vertente isso se deve porque a vida moderna é o que podemos caracterizar como "vida líquida", ou seja, tudo é feito para durar pouco e de forma mutável. Uma vida baseada na perda da essência das coisas. As pessoas atualmente voltam sua atenção para o agora, se ocupando com várias tarefas e deixando a vida de lado (ZYGMUNT, 2001). 
Diante do exposto o presente artigo tem como objetivo estruturar um paralelo de análise entre as praças gregas antigas com as atuais, em específico a Praça dos Imigrantes, localizada no Jardim das Rosas em Presidente Prudente - São Paulo.

\section{METODOLOGIA}

A metodologia adotada foi a análise bibliográfica com conceitos de praças gregas e as atuais. Considerou-se também o aprendizado das disciplinas ministradas no curso de Arquitetura e Urbanismo na Universidade do Oeste Paulista, sendo elas a Evolução Urbana ministrada no ano de 2013 e Urbanismo I ministrada no ano de 2014, ainda realizou-se uma visita in loco na praça do Jardim das Rosas localizada no município de Presidente Prudente-SP.

\section{RESULTADOS}

Obteve-se uma visão da perda grande da funcionalidade da praça, onde era o local de função social, com o intuito de fazer as pessoas se reunirem em grande quantidade para que houvesse discussões, relações amigáveis,familiares e troca de informações veio faltando nas praças atuais, devido a vida caótica urbana e outros fatores como falta de atrativos no local para atrair a população.

\section{DISCUSSÃO: PRAÇA DOS IMIGRANTES - SITUAÇÃO ATUAL}

Com base nas observações in loco foi possível estruturar a tabela qualitativa a seguir, na qual dispõe os tópicos analisados e sua situação atual.

\begin{tabular}{|l|l|}
\hline \multicolumn{2}{|c|}{ Tabela Qualitativa } \\
\hline Vegetação & $\begin{array}{l}\text { A arborização na praça e seu entorno é abundante. Destacam-se as árvores } \\
\text { de grande porte, que proporcionam grandes áreas sombreadas, contudo, elas } \\
\text { ultrapassam os limites das fiações, o que pode ocasionar um problema. } \\
\text { Observar se existem raízes obstruindo o passeio público. }\end{array}$ \\
\hline Manutenção & $\begin{array}{l}\text { O playground encontra-se em mal estado. As lixeiras não são coletadas } \\
\text { irregulares, onde moradores as colocaram amarradas em árvores. A limpeza } \\
\text { da praça está em péssimas condições. Problema com pichações também } \\
\text { podem ser encontrados. }\end{array}$ \\
\hline Acessibilidade & $\begin{array}{l}\text { Existe ao redor da praça quatro guias rebaixadas para a acessibilidade de } \\
\text { portadores de necessidades especiais, porém, dentro da praça em si não } \\
\text { existe essa acessibilidade, há apenas uma rampa que está irregular. }\end{array}$ \\
\hline
\end{tabular}




\begin{tabular}{|l|l|}
\hline Mobiliário & $\begin{array}{l}\text { O mobiliário urbano existente é escasso e mal preservado. O parque foi feito } \\
\text { em madeira e atualmente encontra-se quebrado, gerando risco para as } \\
\text { crianças. Os bancos de concreto estão pichados e quando chove, nota-se o } \\
\text { acúmulo de água. Existe uma placa com a descrição da praça e alguns } \\
\text { "muros" ao seu redor. Mesas de cimento sem o devido espaçamento. }\end{array}$ \\
\hline Entretenimento & $\begin{array}{l}\text { É o que falta na praça, o que existia era o playground porém o mesmo } \\
\text { encontra-se quebrado. Existe uma necessidade de uma melhor exploração } \\
\text { dessa parte. }\end{array}$ \\
\hline
\end{tabular}

Vale pontuar que a praça em questão é abrigada pelo Jardim das Rosas. Local caracteristicamente residencial, contendo apenas um bar como ponto de comércio, socialmente classe média, com casas bem conservadas, ruas largas e áreas de boa arborização.

A praça em si foi projetada para exercer a função que lhe é de conceito, porém ela não cumpre tal atividade completamente, que seria o local de reunião para fins políticos, sociais ou religiosos, ou ainda, onde se desenvolvem atividades de entretenimentos, tendo como vários pontos de referência a UNESP, o Prudenshopping, Walmart, Carrefur, Mufatto Max, valorizando assim a área.

As análises in loco foram feitas em horários variados, o que proporcionou averiguar que a praça tem uma frequência pequena de pessoas, sendo utilizada como área de travessia, perdendo uma grande parte da sua função social, que seria um preceito da praça grega. Onde as pessoas deveriam se encontrar para socializarem e discutirem, um ponto de encontro, porém, a vida moderna limita o cotidiano das pessoas, existe uma necessidade de rapidez na vida urbana, onde a vida caótica e líquida é quem regra a rotina pessoal de cada individuo, devido a esse fato, a praça vem sofrendo essa perda da função.

\section{CONCLUSÃO}

Toda a situação que se encontra na praça também coopera para a falta de frequência e de circulação no local, playgrounds destruídos, a falta de manutenção em relação a lixos espalhados, na calçada da praça se encontra sim 4 guias rebaixadas para deficientes porém para a praça em si só se encontra 1 guia rebaixada e também fora das normas, tudo isso implica na ausência das pessoas nesse devido local, sendo que o terreno tem condições físicas para projetar uma praça de melhor qualidade. 
Essa melhor qualidade seria tanto em questão de espaço, arborização e a situação do seu entorno, o que possibilita a frequência de pessoas de família, pais e filhos e inclusive possibilitaria uma circulação de universitários já que a UNESP se encontra muito próximo.

Há necessidade de saber que a vida atual é diferente de antigamente, existem preocupações novas, tarefas e afazeres novos, e essa vida rápida é o que provavelmente impedem as pessoas de se aproximarem de fato umas das outras. A comunicação é necessária desde a antiguidade e com essa vida rápida e fluida que vivenciamos hoje, fica cada vez mais difícil exercitarmos a comunicação, troca de ideias, experiências, culturas e pensamentos.

Perdeu-se a essência de família, de sair final de tarde com as crianças para jogar bola, de ir aos finais de semana num parque para um piquenique. É necessário resgatar isso e aplicar num contexto atual.

Zygmunt (2001) afirma em seus estudos sobre a modernidade, que tudo é líquido e volátil, as relações humanas não são mais como antes, a vida em família, um grupo de amigos, a vida em casal, entre outras coisas perderam suas essências, tornando-se instáveis.

Não conseguimos mais enxergar nas praças atuais esse exercício de cidadania, não se tem mais como esse ponto de encontro de todos os tipos de pessoas, a sua falta de valor, o seu desuso pode ser sim pelo fator de insolação, falta de manutenção, falta de mobiliário urbano mas também a falta de atratividade para que consiga atrair de novo as pessoas em geral e não apenas crianças e idosos. Porque não poder voltar a ter essa função, o local como ponto de encontro, seja para discutir política e economia?

\section{REFERÊNCIAS}

COULANGES, Fustel. HEMUS. A cidade antiga estudo sobre o culto, o direito, as instituições da Grécia e de Roma; tradução de Jonas Camargo Leite e Eduardo Fonseca. São Paulo, 1975.

DE ANGELIS, Bruno Luiz Domingues et al. Praças: História, Usos e Funções. Maringá, 2005.

DELFANTES, Charles .A Grande História da Cidade, da Mesopotâmia aos Estados Unidos. São Paulo, 2000

ROLNIK, Raquel. O que é a Cidade. São Paulo: BRASILIENSE S. A., 1995.

SUN, Alex. Projeto da Praça - Convívio e Exclusão no Espaço Público. São Paulo, 2008.

ZYGMUNT, Bauman. Modernidade Líquida. Rio de Janeio, 2001. 